\title{
A Case Study on the Content Infiltration of Positive Mental Health Education in Chinese Teaching
}

\author{
$\mathrm{Li} \mathrm{Zhi}^{1}$ \\ ${ }^{1}$ Department of Chinese language and literature, Jinan University, Guangzhou, Guangdong, China \\ Li Zhi: Doctoral candidate of Jinan University, Guangzhou, Guangdong, China. She had worked as a Chinese teacher in a six-year \\ secondary school in Guangzhou for seven years.
}

\begin{abstract}
Conducting the content infiltration of positive mental health education in Chinese teaching is not only the requirement of positive mental health education, but also the requirement of Chinese subject teaching itself. On the basis of summarizing the practical teaching experience, this paper summarizes four methods to conduct the content infiltration of positive mental health education in Chinese teaching, that is: constructing mainstream stories to promote positive identification; bringing students into situation to inspire introspection; reshaping students' positive mind to promote application; arranging writing exercise to promote students' comprehension.
\end{abstract}

\section{Introduction}

Since the central committee of the communist party of China (CPC) first explicitly put forward the requirement of strengthening "quality education" in 1994, the students' mental health has received more and more attention. In 2012, the revised edition of The Guidelines for Primary and Middle School Students' Mental Health Education clearly put forward the overall goal of the mental health education in China as: "Improve all students' psychological qualities; help them to develop a positive, healthy psychological quality; fully develop their mental potential; promote the students' sustainable and harmonious development both in body and spirit; lay a good foundation for their growth and future life [1]." It demonstrates clearly that the Ministry of Education of the People's Republic of China recognizes the concept of positive mental health education and advocates this kind of education. This article proceeds as follows. Part 2 discusses the necessity of content infiltration of positive mental health education in Chinese teaching from the perspective of mental health education and Chinese teaching separately. Part 3 elaborates on four methods of content infiltration of positive mental health education in Chinese. This is the most important part of this article. Many specific teaching examples are mentioned to demonstrate those methods. Part 4 summarizes the crucial two steps of the content infiltration of positive mental health education in Chinese teaching: exploring the useful resources in Chinese textbooks and using various of psychological knowledge. There is still a large number of virgin land to be developed in the field of the content infiltration of positive mental health education in Chinese teaching. Hopefully, this article can serves as a modest spur to induce more people to come forward with their valuable contributions in this field.

\section{The Necessity of Conducting the Content Infiltration of Positive Mental Health Education in Chinese Teaching}

"Positive mental health education" is a concept put forward by Meng Wanjin in 2007, a professor of the Chinese academy of science education. The idea that absorbed the nutrition of positive psychology from the west emphasizes "Chinese outstanding traditional culture, focusing on the harmonious society, the happiness of people and high moral values establishment[2]", "advocating a positive attitude towards everything, treating all kinds of phenomena with a positive attitude, cultivating a positive attitude with positive life experience, acquiring positive emotional experience through positive ways, strengthening positive effects by using positive feedbacks, facing life with positive attitude even in misfortune, and never giving up in pursuing happiness. Positive psychological are the basis of a happy life, so we should keep optimistic mind [2]." As for the implementation of positive mental health education, Professor Meng has put forward six methods, one of which is "infiltration of the related subjects". And "infiltration of the related subjects" contains three meanings: substantive infiltration, formal infiltration and content infiltration. Among them, "content infiltration refers to using the positive factors as much as possible when teaching students basic knowledge and skills, which will produce a positive effect on mental health education [2]."

Chinese is a subject which unifies the tool character and humane character. In the Ordinary High School

\footnotetext{
* Corresponding author: Email: yusanhe@163.com
} 
Chinese Curriculum Standards (2017 edition) issued by the Ministry of Education of the People's Republic of China, some significant ideas related to Chinese teaching are highlighted, such as "forming a high moral and cultural standard", "setting up a positive life ideal", helping students to "love life and enjoy life", helping them to "develop a good foundation for their future life[3]". Therefore, Chinese education and positive mental health education share a common education goal. Literature education is the most important part of Chinese teaching. In fact, literature reading is a doubleedged sword, which may have a positive and also negative impact on readers. The meaning of literary works comes from readers' interpretation. The Chinses teacher is the compass for student who is reading. His interpretation to the works often determines the students' understanding. Therefore, it has become one of the most important tasks for Chinese education workers to review and interpret works from a positive perspective.

The content infiltration of positive mental health education in Chinese teaching is not only the requirement of positive mental health education, but also the requirement of Chinese subject teaching itself.

\section{The Method of Content Infiltration of Positive Mental Health Education in Chinese teaching}

\subsection{Several Significant Concepts}

\subsubsection{Positive Emotion \& Negative Emotion}

"The term positive emotion comes from the early theory of emotional dimensions. This theory believes that all emotions can be constituted by several basic dimensions, which not only can describe the similarity and difference between different emotions, but also measure emotion according to the distance between each other in emotional space. Among them, the widely used mode of emotional dimension is two-dimensional mode, which believes that emotions are composed of two dimensions: one is called activation or awakening level, ranging from weak to strong; the other is called happiness, ranging from positive to negative. The latter can also be called the nature of emotions. And we call the one that is at the positive valence of happiness, the one that has pleasant feelings, positive emotions, and the one that has negative valence, negative emotions [4]". Positive psychology believes that negative emotions can be transformed into positive emotions by changing cognition, and positive emotions can eliminate the psychological effects of negative emotions.

\subsubsection{Character Strength \& Character Weakness}

The American psychologists Martin Seligman and Christopher Peterson had "great interest in positive youth development", so they "assembled a team of social scientists to produce the VIA Classification of Character
Strengths[5]". Character strengths are positive dispositions, when identifying character strength, one of the criteria is that the character strength "has a nonfelicitous opposite: has obvious antonyms that are "negative'[5]". In this article, the opposite of the character strength is called character weakness. Positive psychologist holds that character strength can be cultivated[6], and people's happiness is closely related to character strength[4].

\subsubsection{Positive Factors \& Negative Factors}

The creation of literary works is a release of some psychological tension for the individual writer. Therefore, there will be both positive and negative emotions in literary works. Both character strength and character weakness of the writer will be showed in the literary works. In the following passage, the positive emotions and the character strengths of the author showed in the text will be called the positive factors,

and the negative emotions and the character weakness of the author showed in the text will be called the negative factors.

\subsection{Elaborating on Four Methods}

Middle school year is a key period for an individual to transit from childhood to adulthood and to form an outlook on life, values, and on world. Students' life experience is not rich, and they are more susceptible to literary works than adults. Besides, they are more likely to consider others' experiences as their reference standards and incorporate into their own thinking patterns. Therefore, Chinese teachers should make effort to negate or minimize the negative impact brought by negative factors in the text on the psychology of the students, and they should try their best to maximize the positive impact brought by positive factors in the text on the psychology of the students.

According to Chinese teaching experience, four methods are summarized as follows:

\subsubsection{Constructing Mainstream Stories to Promote Positive Identification}

The mainstream stories talked about here refer to those which contain positive and mainstream values based on the writers' life experiences. According to Hayden White's historical narratology, "Metahistory" is irreducible. "Elements in historical field are organized in to a chronicle" and "the chronicle is organized into a story", "the historian arrange the events in the chronicle into a hierarchy of significance" [7]. Therefore, Chinese teachers do not have to be obsessed with the narrow historical "real" concept. They only need to employ their imaginative and purposeful understandings to bind the fragments of history to construct the writers' mainstream stories based on their life experience, which conforms to our educational purposes. This method is applicable to the teaching of text with positive factors dominant, and also text with negative factors dominant. 
To the text dominated by positive factors, mainstream stories can be constructed by supplementing the stories of the writers' life experiences. For example, Remolding Life, a text in the PEP edition of Chinese textbook for the seven grade students, tells a story about little Helen Keller. In the text, little Hellen's thirst for knowledge, perseverance, fierce love for life and sincere gratitude for others have a positive impact on the students. They are moved by little Hellen's character strengths. If the teacher supplements Helen Keller's striving experience and extraordinary achievements in the teaching process, the students may further realize the writer's great enthusiasm for life, and they may marvel at the miracles of life which were created by the disabled girl. The stories supplemented by the teacher can form a synergy with the texts to better stimulate the students' characters of perseverance, tenacity, and their love for life.

To the text dominated by passive factors, constructing and telling a mainstream story requires a lot of good ideas from the teacher, because the teacher has to construct an image that is completely different from the writer who showed negative emotions or character weakness in the text. The teacher should grasp the opportunity to make positive and psychologically suggestive comments to construct a positive image of the writer in the students' mind, so that the students' can understand the emotions and characters exhibited by the writer in the textbook in a comprehensive perspective. Finally, the teacher would successfully negate or minimize the passive impacts on the students and make them inspired by the positive factors in the mainstream story. The Stories in Xiang JiXuan (Xiang JiXuan is the name of a study), a text of the senior high school Chinese textbook of Cantonese edition, is a prose written by Gui Youguang in the Ming Dynasty. Recalling the past time and the family members who have passed away, Gui Youguang showed his sadness towards the people passed away and his pain caused by disillusionment in the prose. If the teachers don't pay attention to the methods of teaching this text, the students are inclined to form a negative psychological judgment that people can not change the painful life and they should not work hard. During the process of teaching, the teacher supplemented the explanation of Gui Youguang's unfortunate life. He fails in the Chinese imperial examinations and bears the bereavement caused by the loss of three spouses, two daughters and one son. After telling the author's miserable life experience, the teacher made the following comments: "Various unbearable blows have come to Gui Youguang's way, but he has not been indulged in adversity. He is like the grass in the blast, and the more violent storms he experiences, the more perseverant and tenacious he becomes. This is the strength and beauty unique for life. Next, the teacher further improved the mainstream story: "Let's pay attention to Gui Youguang's confidence and courage. Even he passed the imperial examination at the age of sixty, he still held the post of the magistrate of Changxing County. He was neither overbearing nor servile and governed according to his own principles. Besides, in a time when Yangming Philosopy was dominant, he still confidently adhered to his own value judgment, and insist on the Neo-Confucianism of Zhuzi's. With the Classist School dominating the literary world and the influence of Wang Shizhen prevailing, he dared to blame Wang Shizhen for being mediocre with his profound writing skills. And he is remembered as 'a man of letters ranked No.1 in the Ming Dynasty'." After finishing making a mainstream story, the teacher made the following summarized comments: "Facing the irresistible sufferings in life, Gui Youguang is like a camel in the desert, carrying the weight of life and silently completing his long journey. In spite of endless sadness, he still treasures his life. He doesn't immerse himself in sorrow, but merges it with the article to express his inmost emotions. In addition, he doesn't give up in spite of overwhelming pain, and lives with dignity and glory. Maybe life would be an endless war, but we shouldn't give in to fate. We should forge a worthy soul in the struggle against fate, and show the dignity and glory of life with incessant action. This is the enlightenment we can gain from Gui Youguang's life experience. Gui is like a "Gorgeous Flower" which grows and blooms on the wasteland full of the sadness and illusion. May the fragrance of the flower of Gui Youguang's spirt pervades your heart forever, and encourages you to make an arduous journey through your life, regardless of obstacles and dangers." In this way, although the focus of the lesson is to understand the "sadness" that runs through the article: the sadness of losing some family members (his mother, grandmother and wife), the unsatisfied expectation of the ideal (has no fame and no fortune). However, after analyzing the tragic experience of Gui Youguang in the article and by constructing a mainstream story, the negative psychological influence which is caused by negative factors of the article can be eliminated. Then the students would appreciate the attitude of Gui Youguang that never yield to destiny, they would bear in mind one thing that no matter in what kind of circumstances, one must be strong and bravely pursue the value and meaning of life. In this way, the teacher successfully completed the task of dispelling the negative influences on the students and promote their positive psychological identification.

\subsubsection{Bringing Students into Situation to Inspire Introspection}

The situational teaching method works well with positive teaching material. It not only helps students to understand the literal meaning of the works but also inspire their self- introspection. Generally speaking, it is hard for students to step into a writer's creation world, so the students may have some difficulties to understand the writer's psychology in creation. Teacher's demonstration can help them a lot. Leading the students by demonstrating by teachers themselves does not mean the same as thinking for the students. The intention is to represent the character strengths of the writer to the full. After bringing the students into the situation of the work, the teacher could make the students to introspect and 
could make them have a further identification to writer's character strengths.

For instance, when teaching Returning to My Farm (III), a poem in PEP edition of Chinese textbook for the eight grade students, firstly the teacher asked students to find the lines that showed the tough side of life in the poem, which were "The peas are few, but weeds grow in their stead" talking about bad growth of the plant, "At dawn I rise to clear the dust and filth, bring back my hoe with moon above my head" talking about going to work in the early morning, coming home after dusk and farm work being really tiring. After this, the teacher provided more information about the author Tao Yuanming's background, telling them how tough his life was and that his relatives couldn't accept his choice of life. Then the teacher led the students to think about this question: " 'Bring back my hoe with moon above my head' is always regarded the most poetic line in the poem, one coming back home with the moon. But how could Tao Yuanming find the beauty in life when he had to do the heavy labor work every day just to make ends meet for his family, and also when he had to put up with loneliness from not being understood by his relatives? Use your imagination. Think yourself as Tao Yuanming, who lived thousands of years ago. What would you think of, as you work from day to night, as you walk alone on that rural country path in shabby clothes with the hoe on your shoulder? And try to think as close to the original artistic conception the poem created as possible."After students describing their imagination, the teacher demonstrated what she imagined:" it was after sunset, I was walking back home after a long day's work. My body was so tired but I felt pretty relaxed. Things around me are all turning black as night went on. No red flowers, no green trees, no running rabbits or flying birds, I felt lonely. But as I raised my head, the moon was shining, which warmed my heart. I was a little touched and cheered. I still got the moon with me, keeping my company. I was not alone. The moon was like my pure heart. How could one find a twin soul like this? I wanted to take it home, so it wouldn't be lonely either, and I could stay pure and feel peaceful as well.'With students' description and the teacher's demonstration, students could engage in the situation more naturally and show deeper understanding of Tao Yuanming's precious personality -- how he could stay positive in tough situation, how he could stick to his faith and develop a poetic personality. Through situational teaching method, students could experience Tao Yuanming's positive mind and learn about his upward characters-- being relaxed and confident, sticking to what you believe in, staying calm despite others' suspicion and seeking the beauty of life though in adversity.

\subsubsection{Reshaping Students' Positive Mind to Promote Application}

According to Foucault, sometimes, power has a positive effect. It helps to construct one's life. People would be incited by power and construct their life in accordance with what they believe to be truth[8]. Undoubtedly, teachers, the masters of knowledge in classes, are the ones who possess power, and what they take as "truth" are pretty influential on students. What positive thoughts the teachers lead the students to believe in are likely to stay in students' mind for a long time and work into their personality. Teachers should make some ways to explain the positive thoughts in the text as close to the students' life as possible, so that students could apply them into their own life.

When teaching the Prologue of Hosting Banquet for Cousins in Garden in Spring Night, for instance, the teacher started by telling the life story of Li Bai, such as his struggle for his political aspiration, to present his persistence and his character strengths. Then the teacher talked about Li Bai's life motto: seize the day, and made the students understand that Li Bai's life motto is a kind of positive thoughts which could enable him to face setbacks with optimistic attitude and to keep on pursuing his dreams without frustration. Then, the teacher proposed: "Now let's take Li Bai as our life model, and think about our own life, about how to live our high school life, with so much pressure from study." The intention was to encourage students to apply Li Bai's life wisdom to their own life.Afterwards, the teacher gave her review on students' answers: "We should struggle to make our youth valuable and meaningful, and also pay attention to the beauty and happiness in life in the meantime. Be happy as we strive in life. That's how we make high school life worth living. Life is beautiful and precious. Stay positive and defeat negative things. Let's laugh at the disappointments and sorrows of life. "After applying Li Bai's optimistic attitude to their own life, students would be inspired to introspect themselves. They would be encouraged to think on the bright side when dealing with pressure from study, and they would be encouraged to welcome each day of life with happy mood.

\subsubsection{Arranging Writing Exercise to Promote Students' Comprehension}

Writing is a narrative that originates from the heart. In addition to use the textbook to give students positive psychological guidance in class, teachers have to assign writing exercise to promote their comprehension. Teachers can assign different writing tasks according to different teaching purposes. To be specific, there are three kinds of writing tasks:

\section{Reinforcing-identification Writing Tasks}

It adapts Michel Foucault's notion of "powerknowledge". The purpose of assigning this kind of writing task is to let students comprehend the class content, internalize their positive thinking learned in the class so as to strengthen their character strengths. To assign this kind of homework, the teacher should extract the key points of positive mental health education and draw it into the topic that students are required to finish the composition. For example, the teacher had assigned such homework after teaching the prologue of hosting banquet for cousins in garden in spring night as follows: "We ought to strive forward in daily life, but not to 
forget to enjoy our life. This is a life wisdom that Li Bai leave behind us. Please write an argumentative writing of about 800 words on the topic 'progress and happiness: a duet of harmonious life', discussing about your opinions toward Li Bai's life wisdom. "In this case, the students are asked to demonstrate the correctness of the given point. They are likely to be forced to agree with the "truth" constructed by the "power", and be conquered by the "truth", that is to say, they have internalized Li Bai's positive attitude.

\section{Externalizing-problem writing task}

"'Externalizing' is an approach to therapy that encourages persons to objectify and, at times, to personify the problems that they experience as oppressive. In this process, the problems become a separate entity and thus external to the person or relationship that was ascribed as the problem. Those problems that are considered to be inherent, as well as those relatively fixed qualities that are attributed to persons and to relationships, are rendered less fixed and less restricting [8]." "By mapping the problem's relations by way of externalization of its relations and effects on the client, the problem becomes the problem -not the client -an adage of narrative therapy [8]." According to Michael White, teachers could assign externalizingproblem writing task to help students to clarify the problems that are bothering them in life, and to make psychological adjustment so as to obtain a positive attitude. For example, the teacher have assigned the following task after finishing the teaching of Prelude to Water Melody: "Men have sorrow and joy; they part or meet again; The moon is bright or dim and she may wax or wane. Life is not perfect and hardship may come one after another, but we should not sigh all the time and indulged in trouble, and even to repudiate the life because of the imperfect in life. We should dispel the worry by passion and optimism. Reflecting on your life, do you have any worries? Can you face it with a positive attitude? Please write the semi-topic composition on the topic 'Finally, I can face with a positive attitude'." Although this psychological adjustment is only a simulation conducted through writing, but the thinking model of resolving troubles and facing difficulties optimistically will be preserved by the students, and thus helping them to look at life optimistically.

III. Reconstructing-experience writing task

According to Michael White, "the structuring of a narrative requires recourse to a selective process in which we prune, from our experience, those events that do not fit with the dominant evolving stories that we and others have about us[8]." "Not only do the stories that persons have about their lives determine the meaning that they ascribe to experience, but these stories also determine which aspects of lived experience are selected out for the ascription of meaning [8]." Keeping an optimistic mind to review the past and re-telling stories enables students to reflect on their previous attitude in the process of reconstructing experiences, and to rebuild an optimistic ego in re-telling. After completing the class of Returning to My Farm(III), the teacher have assigned the following writing task: "Maybe in others' opinions,
Tao Yuanming lives a poor and lonely life after returning to the farm. However, we can feel poetic beauty through his poem. Sadness and happiness, joy and sorrow are all depends on how we look at life. Please write a composition of about 600 words on the topic 'my beautiful life'." Language has a magical power that gives meaning to people's experiences, helps people construct their lives, and reshape themselves. By completing such writing tasks, students can gradually learn to tell their stories positively so that building their optimistic personality.

\section{Conclusion}

Designing a good content is a key part in teaching since it directly relates to the teaching effect. In order to permeate positive mental health education into Chinese teaching, teachers need to explore useful resources in Chinese textbooks that can cultivate the students' character strengths. They also need to employ various psychological knowledge and means, such as positive psychology, narrative therapy, bibliotherapy, writing therapy to cultivate the students' positive thinking. On the one hand, it requires Chinese teachers to have a solid foundation in literature; On the other hand, teachers have to keep learning positive psychology and other related psychology knowledge. There still has a large number of positive mental education resources in Chinese textbooks that are waiting to be explored. If teachers can integrate these resources and make full use of them, students can acquire more cultural edification when they study Chinese, and they can possess an optimistic heart. In this way, both Chinese teaching and positive mental health education can achieve good results.

\section{Reference:}

1. The Ministry of Education of the People's Republic of China.(2012) The Guidelines for Primary and Middle School Students' Mental Health Education (revised in 2012). Retrieved October 28, 2018, from http://old.moe.gov.cn/publicfiles/business/htmlfiles /moe/s3325/201212/145679.html

2. Meng Wanjin. et al. Positive Mental Health Education in China. Educational Science Publishing House, 1-30, (2017)

3. The Ministry of Education of the People's Republic of China.(2018) .Ordinary High School Chinese Curriculum Standards (2017 edition) . Retrieved October 28, 2018, from http://www.moe.gov.cn/srcsite/A26/s8001/201801/t 20180115_324647.html

4. Liu Xiangping Eds. Contemporary Positive Psychology, China light industry press, 53, 124, (2010)

5. Christopher Peterson. A primer in Positive Psychology. Trans. Hou Yubo, Wang Fei, et al. China Machine Press, 312,77, (2010) 
6. Tao Xinhua. Positive Psychology in Education. East China Normal University Press, 138, (2017)

7. Hayden White. Metahistory: The Historical Imagination in Nineteenth-Century Europe. Trans. Chen Xin. Yilin Press, 7-8, (2004)

8. Michael White, David Epston. Narrative Means to Therapeutic Ends. Trans. Liao Shide. East China University of Science and Technology Press, 10-34 (2013) 